\title{
CAAC Boranes. Synthesis and characterization of cyclic (alkyl) (amino) carbene borane complexes from $\mathrm{BF}_{3}$ and $\mathrm{BH}_{3}$
}

\author{
Julien Monot ${ }^{1,2}$, Louis Fensterbank ${ }^{* 1}$, Max Malacria*1, Emmanuel Lacôte*1, \\ Steven J. Geib² and Dennis P. Curran*2
}

\section{Full Research Paper}

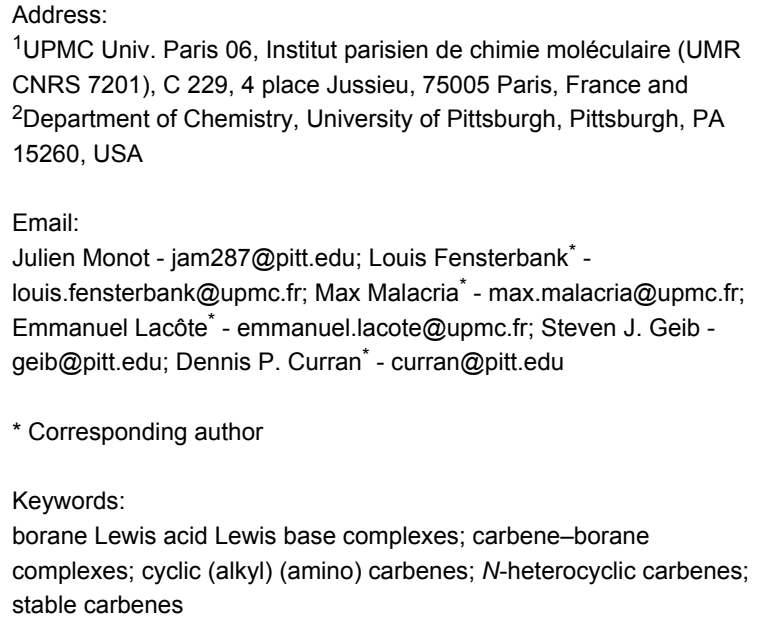

${ }^{1}$ UPMC Univ. Paris 06, Institut parisien de chimie moléculaire (UMR CNRS 7201), C 229, 4 place Jussieu, 75005 Paris, France and ${ }^{2}$ Department of Chemistry, University of Pittsburgh, Pittsburgh, PA 15260, USA

Email:

Julien Monot - jam287@pitt.edu; Louis Fensterbank ${ }^{*}$ louis.fensterbank@upmc.fr; Max Malacria* - max.malacria@upmc.fr; Emmanuel Lacôte* - emmanuel.lacote@upmc.fr; Steven J. Geib geib@pitt.edu; Dennis P. Curran* - curran@pitt.edu

${ }^{*}$ Corresponding author

Keywords:

borane Lewis acid Lewis base complexes; carbene-borane

complexes; cyclic (alkyl) (amino) carbenes; $N$-heterocyclic carbenes; stable carbenes

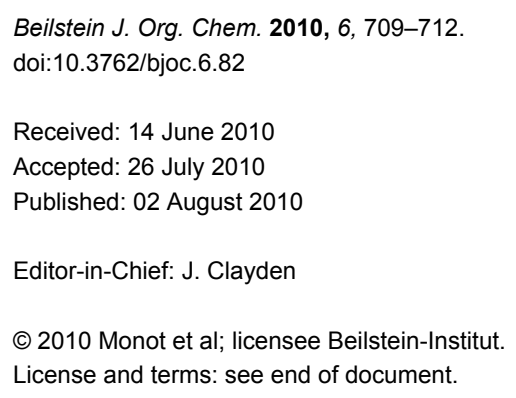

\begin{abstract}
In situ formation of two cyclic (alkyl) (amino) carbenes (CAACs) followed by addition of $\mathrm{BF}_{3} \cdot \mathrm{Et}_{2} \mathrm{O}$ provided the first two examples of $\mathrm{CAAC}-\mathrm{BF}_{3}$ complexes: 1-(2,6-diisopropylphenyl)-3,5,5-trimethyl-3-phenylpyrrolidin-2-ylidene trifluoroborane, and

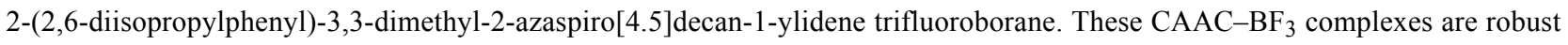
compounds that are stable to ambient laboratory conditions and silica gel chromatography. They were characterized by spectroscopy and X-ray crystallography. In contrast, a CAAC complex with borane $\left(\mathrm{BH}_{3}\right)$ was readily formed in situ according to ${ }^{1} \mathrm{H}$ and ${ }^{11} \mathrm{~B}$ NMR analysis, but did not survive the workup conditions. These results set the stage for further studies of the chemistry of CAAC boranes.
\end{abstract}

\section{Introduction}

Lewis acid/Lewis base complexes of $N$-heterocyclic carbenes and boranes (NHC-boranes) are readily prepared from NHC's and boranes by direct complexation [1-4]. Unlike many other classes of Lewis base complexes of boranes with neutral molecules (ethers, sulfides, etc.), NHC-borane complexes are highly stable in diverse environments. Complexes such as those shown 
in Figure 1 are white solids that can often be chromatographed if desired. Many such complexes resist decomplexation, oxidation, and both acidic and basic hydrolysis. Such NHC-boranes are beginning to be used as synthetic reagents, with applications in radical [5-9], ionic [10,11] and organometallic [12] reactions. They are also precursors for making higher complexes with unusual bonding patterns such as boron-boron double bonds [3], or for making unusual reactive intermediates on boron $[6,7,13]$.

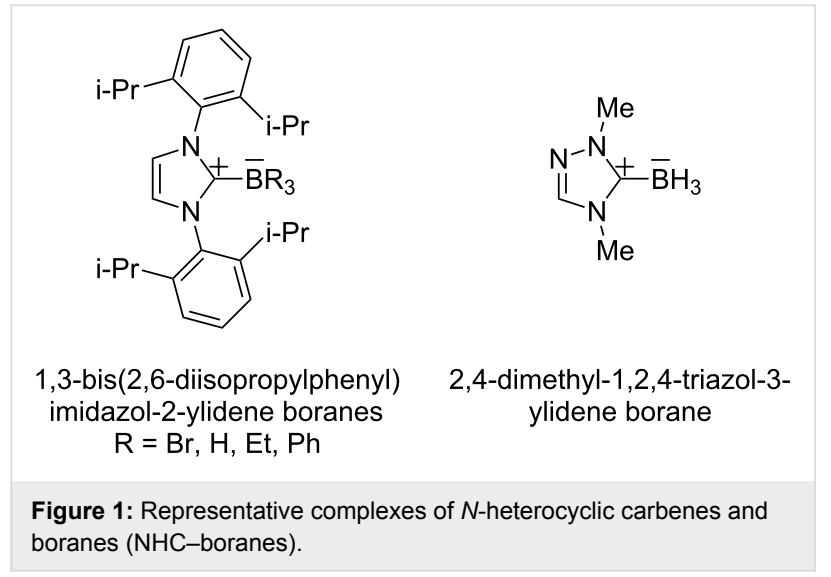

Most of the first generation carbene-boranes have been made from $N$-heterocyclic carbenes in which the carbene carbon is stabilized by two donating nitrogen atoms (imidazolylidene, triazolylidene, etc) or other heteroatoms (phosphorous, silicon, oxygen) [14-18]. An exception is Bertrand's $\mathrm{BF}_{3}$ complex of an acyclic (amino) (aryl) carbene in which the aryl group is 9-anthracenyl [19]. This complex, whose structure is shown in Figure 2, has also two cation stabilizing groups on the carbene carbon.

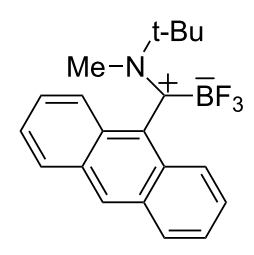

Figure 2: Bertrand's amino anthracenyl carbene trifluoroborane complex.

Accordingly, it is interesting to study borane complexes of other types of carbenes. Recently, Bertrand introduced, cyclic (alkyl) (amino) carbenes, or CAACs, as a new class of carbene complex in which the central carbene carbon is stabilized by only one nitrogen atom [20-23]. Herein we report the synthesis and characterization (including $\mathrm{X}$-ray structures) of two stable $\mathrm{CAAC}-\mathrm{BF}_{3}$ complexes. We also show through spectroscopic studies that a representative $\mathrm{CAAC}-\mathrm{BH}_{3}$ complex can be generated in solution.

\section{Results and Discussion}

CAAC trifluoroborane complexes $\mathbf{3 a}$ and $\mathbf{3 b}$ were readily prepared as summarized in Scheme 1. Deprotonation of the 3,4dihydro- $2 H$-pyrrolium hydrogen dichloride salt 1 a with NaHMDS in THF at $-78{ }^{\circ} \mathrm{C}$, followed by warming to room temperature gave a pale yellow solution of the free carbene $\mathbf{2 a}$ [20]. A broad resonance at $-312 \mathrm{ppm}$ in the ${ }^{13} \mathrm{C}$ NMR spectrum of this solution indicated that $\mathbf{2 a}$ had formed. Boron trifluoride etherate $\left(\mathrm{BF}_{3} \cdot \mathrm{Et}_{2} \mathrm{O}\right)$ was then added at $-78^{\circ} \mathrm{C}$ and the resulting solution was stirred overnight. Rapid filtration through silica gel afforded the pure complex 3a (1-(2,6-diisopropylphenyl)-3,5,5-trimethyl-3-phenylpyrrolidin-2-ylidene trifluoroborane) as white crystals in $61 \%$ yield. CAAC borane $\mathbf{3 b}$ (2-(2,6-diisopropylphenyl)-3,3-dimethyl-2-azaspiro[4.5]decan1 -ylidene trifluoroborane) was made by a similar procedure starting from triflate salt $\mathbf{1 b}$ and was isolated in $64 \%$ yield.

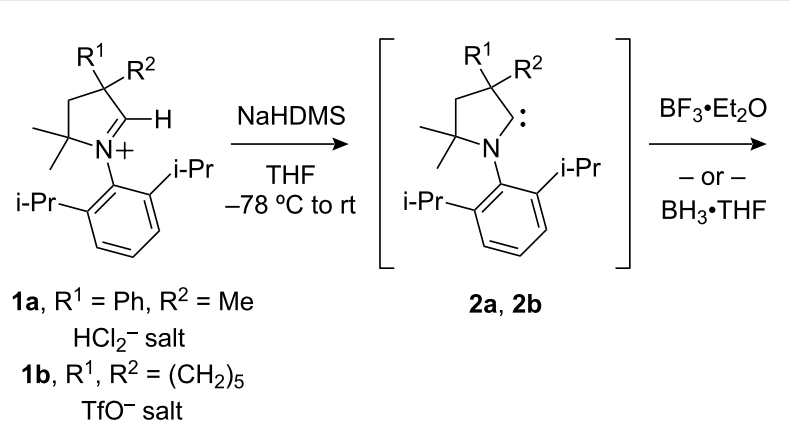

$\mathrm{TfO}^{-}$salt

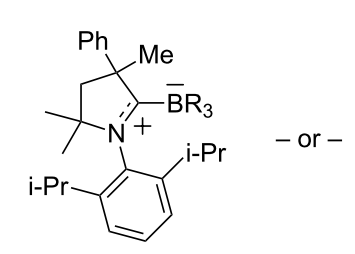

$$
\begin{gathered}
\text { 3a, } R=F \text {, stable } \\
4 a, R=H,
\end{gathered}
$$$$
\text { detected in solution }
$$

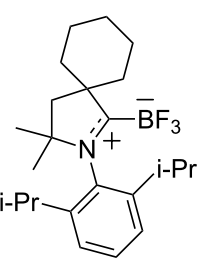

3b
Scheme 1: Synthesis of stable $C A A C-\mathrm{BF}_{3}$ complexes $\mathbf{3 a}$ and $\mathbf{3 b}$ and in situ generation of $\mathrm{CAAC}-\mathrm{BH}_{3}$ complex $4 \mathrm{a}$.

CAAC boranes $\mathbf{3 a}$ and $\mathbf{3 b}$ were obtained as white crystals, and the structure of a single crystal of each was solved by X-ray diffraction. Two views of each structure are shown in Figure 3. Of special interest are the lengths of the $\mathrm{C}_{\text {carbene }}-\mathrm{N}$ bonds. At 1.294(3) $\AA$ for 3a and 1.293(3) $\AA$ for 3b, these bonds are significantly shorter than analogous bonds on other $\mathrm{NHC}-\mathrm{BF}_{3}$ complexes where the carbene carbon has two nitrogen substituents (1.338(5)-1.355(5) $\AA$ ) [24,25]. Instead, these bond lengths are closer to that of the $\mathrm{BF}_{3}$ complex of the amino- 


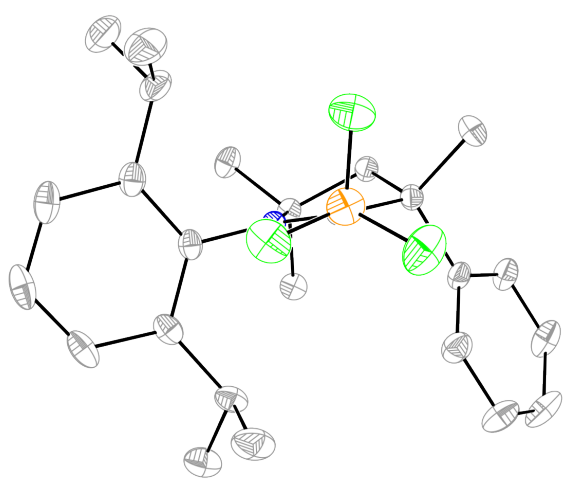

3a (front view)

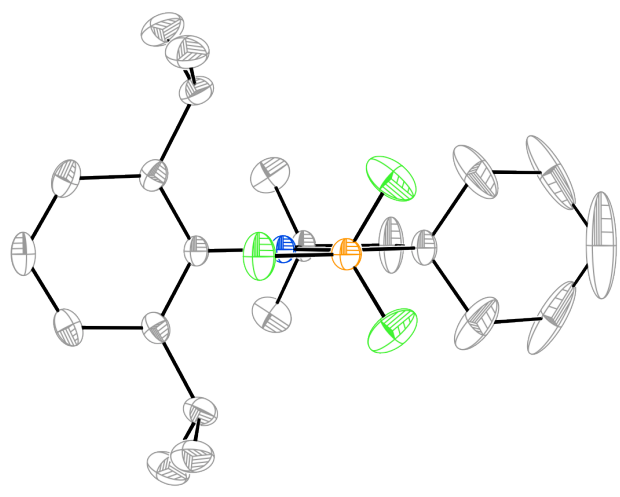

$\mathbf{3 b}$ (front view)

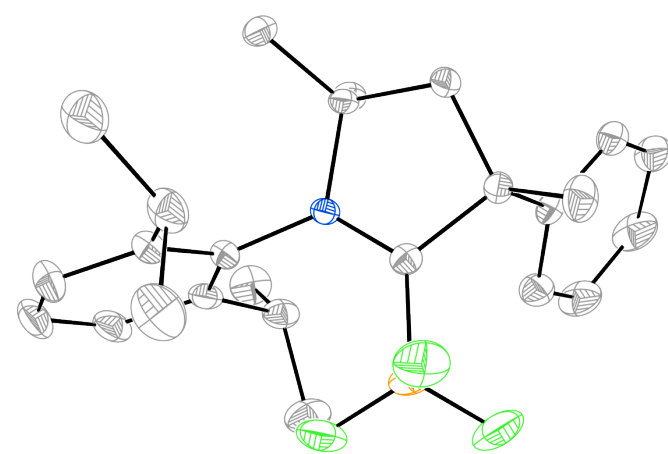

3a (top view)

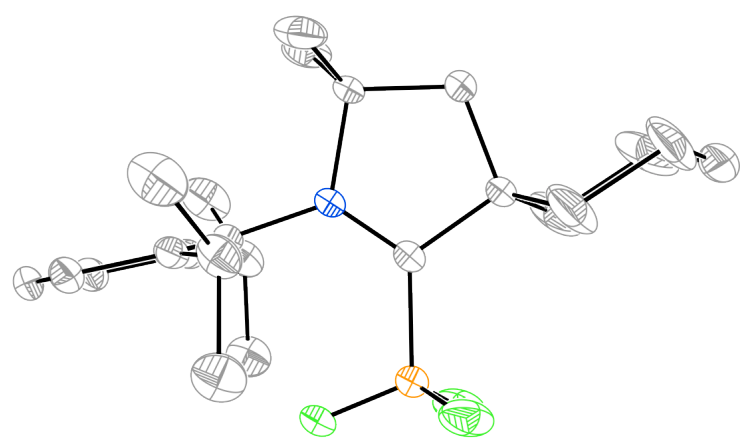

3b (top view)

Figure 3: X-Ray crystal structures of CAAC-BF 3 complexes $\mathbf{3 a}$ (top) and $\mathbf{3 b}$ (bottom)

anthryl-carbene (1.301(2) $\AA$ ) shown in Figure 2 [19]. Presumably, this is because there is more demand on the lone nitrogen of CAAC complex to stabilize the positive charge than when two nitrogen atoms are present. In contrast, the $\mathrm{C}_{\text {carbene }}-\mathrm{B}$ bond lengths of 3a (1.674(3) $\AA$ ) and $\mathbf{3 b}(1.681(3) \AA)$ are somewhat longer than those in other $\mathrm{NHC}-\mathrm{BF}_{3}$ complexes $(1.635(5)-1.668(6) \AA)[24,25]$.

To conclude this preliminary study, we briefly attempted formation of the borane complex $4 \mathbf{a}$ by generation of carbene $\mathbf{2 a}$ as above, followed by the addition of $\mathrm{BH}_{3} \bullet$ THF. Indeed, complex 4a was directly formed in situ as evidenced by ${ }^{11} \mathrm{~B}$ NMR spectroscopy. The resonance for $\mathrm{BH}_{3} \cdot \mathrm{THF}$ was absent and in its place was a new quartet at $-30.0 \mathrm{ppm}$. Both the chemical shift and multiplicity of this resonance are consistent with the CAAC-borane structure $4 a$. The ${ }^{1} \mathrm{H}$ NMR spectrum of the reaction mixture also showed the formation of $\mathbf{4 a}$ (see Supporting Information File 1).
The reaction mixture was allowed to stand for $15 \mathrm{~h}$, during which time the ${ }^{11} \mathrm{~B}$ NMR spectrum was unchanged. This suggests that complex $\mathbf{4 a}$ is thermally stable. However, standard workup and evaporation as used for NHC-boranes and $\mathrm{CAAC}-\mathrm{BF}_{3}$ complexes $\mathbf{3} \mathbf{a}$ and $\mathbf{3 b}$ did not provide $\mathbf{4 a}$. Evidently, 4a is not as stable towards isolation as the $\mathrm{BH}_{3}$ complexes shown in Figure 1. Nonetheless, it should still be possible to generate this complex in situ and use it directly for onward reactions.

\section{Conclusion}

In summary, we have synthesized the first CAAC borane complexes. The complexes of trifluoroborane $\left(\mathrm{BF}_{3}\right)$ are stable and were isolated as pure solids and fully characterized by spectroscopic analysis and X-ray crystallography. The borane $\left(\mathrm{BH}_{3}\right)$ complex was characterized in situ by NMR spectroscopy, but did not survive workup and isolation. These results set the stage for further studies of the chemistry of CAAC boranes. 


\section{Supporting Information}

\section{Supporting Information File 1}

Procedures and characterization of the new complexes.

[http://www.beilstein-journals.org/bjoc/content/

supplementary/1860-5397-6-82-S1.pdf]

\section{Supporting Information File 2}

Cif file of crystal structure of compound $\mathbf{3 a}$.

[http://www.beilstein-journals.org/bjoc/content/

supplementary/1860-5397-6-82-S2.cif]

\section{Supporting Information File 3}

Cif file of crystal structure of compound $\mathbf{3 b}$.

[http://www.beilstein-journals.org/bjoc/content/

supplementary/1860-5397-6-82-S3.cif]

\section{Acknowledgements}

This work was supported by grants from the US National Science Foundation (CHE-0645998), UPMC, CNRS, and the French Agence Nationale de la Recherche (ANR, BLAN0309 Radicaux Verts, and 08-CEXC-011-01 Borane). We thank H. Rousselière and P. Herson (IPCM, Paris) for solving one of the crystal structures. We thank Dr. G. Mignani of Rhodia, Inc. for generously providing salt $\mathbf{1 a}$.

\section{References}

1. Kuhn, N.; Henkel, G.; Kratz, T.; Kreutzberg, J.; Boese, R.; Maulitz, A. H. Chem. Ber. 1993, 126, 2041-2045. doi:10.1002/cber.19931260913

2. Ramnial, T.; Jong, H.; McKenzie, I. D.; Jennings, M.; Clyburne, J. A. C. Chem. Commun. 2003, 1722-1723. doi:10.1039/b301416a

3. Wang, Y.; Quillian, B.; Wei, P.; Wannere, C. S.; Xie, Y.; King, R. B.; Schaefer, H. F., III; v. R. Schleyer, P.; Robinson, G. H. J. Am. Chem. Soc. 2007, 129, 12412-12413. doi:10.1021/ja075932i

4. Yamaguchi, Y.; Kashiwabara, T.; Ogata, K.; Miura, Y.; Nakamura, Y.; Kobayashi, K.; Ito, T. Chem. Commun. 2004, 2160-2161. doi:10.1039/b405459h

5. Ueng, S.-H.; Makhlouf Brahmi, M.; Derat, É.; Fensterbank, L.; Lacôte, E.; Malacria, M.; Curran, D. P. J. Am. Chem. Soc. 2008, 130, 10082-10083. doi:10.1021/ja804150k

6. Matsumoto, T.; Gabbaï, F. P. Organometallics 2009, 28, 4252-4253. doi:10.1021/om900476g

7. Ueng, S.-H.; Solovyev, A.; Yuan, X.; Geib, S. J.; Fensterbank, L.; Lacôte, E.; Malacria, M.; Newcomb, M.; Walton, J. C.; Curran, D. P. J. Am. Chem. Soc. 2009, 131, 11256-11262. doi:10.1021/ja904103x

8. Walton, J. C.; Makhlouf Brahmi, M.; Fensterbank, L.; Lacôte, E.; Malacria, M.; Chu, Q.; Ueng, S.-H.; Solovyev, A.; Curran, D. P. J. Am. Chem. Soc. 2010, 132, 2350-2358. doi:10.1021/ja909502q

9. Tehfe, M.-A.; Makhlouf Brahmi, M.; Fouassier, J.-P.; Curran, D. P.; Malacria, M.; Fensterbank, L.; Lacôte, E.; Lalevée, J. Macromolecules 2010, 43, 2261-2267. doi:10.1021/ma902492q
10. Chu, Q.; Makhlouf Brahmi, M.; Solovyev, A.; Ueng, S.-H.; Curran, D. P.; Malacria, M.; Fensterbank, L.; Lacôte, E. Chem.-Eur. J. 2009, 15, 12937-12940. doi:10.1002/chem.200902450

11. Lindsay, D. M.; McArthur, D. Chem. Commun. 2010, 46, 2474-2476. doi:10.1039/c001466d

12. Monot, J.; Makhlouf Brahmi, M.; Ueng, S.-H.; Robert, C.; Desage-El Murr, M.; Curran, D. P.; Malacria, M.; Fensterbank, L.; Lacôte, E. Org. Lett. 2009, 11, 4914-4917. doi:10.1021/ol902012c

13. Braunschweig, H.; Chiu, C.-W.; Radacki, K.; Kupfer, T. Angew. Chem., Int. Ed. 2010, 49, 2041-2044. doi:10.1002/anie.200906884

14. Alcaraz, G.; Reed, R.; Baceiredo, A.; Bertrand, G. Chem. Commun. 1993, 1354-1355.

15. Lambert, C.; Lopez-Solera, I.; Raithby, P. R. Organometallics 1996, 15, 452-455. doi:10.1021/om950427s

16. Tamm, M.; Lügger, T.; Hahn, F. E. Organometallics 1996, 15, 1251-1256. doi:10.1021/om950773+

17. Merceron, N.; Miqueu, K.; Baceiredo, A.; Bertrand, G. J. Am. Chem. Soc. 2002, 124, 6806-6807. doi:10.1021/ja026556z

18. Snead, D. R.; Ghiviriga, I.; Abboud, K. A.; Hong, S. Org. Lett. 2009, 11, 3274-3277. doi:10.1021/ol9013156

19. Cattoën, X.; Gornitzka, H.; Bourissou, D.; Bertrand, G. J. Am. Chem. Soc. 2004, 126, 1342-1343. doi:10.1021/ja0396854

20. Lavallo, V.; Canac, Y.; Präsang, C.; Donnadieu, B.; Bertrand, G. Angew. Chem., Int. Ed. 2005, 44, 5705-5709. doi:10.1002/anie.200501841

21. Lavallo, V.; Canac, Y.; DeHope, A.; Donnadieu, B.; Bertrand, G. Angew. Chem., Int. Ed. 2005, 44, 7236-7239. doi:10.1002/anie.200502566

22. Jazzar, R.; Dewhurst, R. D.; Bourg, J.-B.; Donnadieu, B.; Canac, Y.; Bertrand, G. Angew. Chem., Int. Ed. 2007, 46, 2899-2902. doi:10.1002/anie.200605083

23. Zeng, X.; Frey, G. D.; Kinjo, R.; Donnadieu, B.; Bertrand, G. J. Am. Chem. Soc. 2009, 131, 8690-8696. doi:10.1021/ja902051m

24. Arduengo, A. J., III; Davidson, F.; Krafczyk, R.; Marshall, W. J.; Schmutzler, R. Monatsh. Chem. 2000, 131, 251-265. doi: $10.1007 / s 007060070101$

25. Nielsen, D. J.; Cavell, K. J.; Skelton, B. W.; White, A. H. Inorg. Chim. Acta 2003, 352, 143-150. doi:10.1016/S0020-1693(03)00143-9

\section{License and Terms}

This is an Open Access article under the terms of the Creative Commons Attribution License (http://creativecommons.org/licenses/by/2.0), which permits unrestricted use, distribution, and reproduction in any medium, provided the original work is properly cited.

The license is subject to the Beilstein Journal of Organic Chemistry terms and conditions: (http://www.beilstein-journals.org/bjoc)

The definitive version of this article is the electronic one which can be found at: doi:10.3762/bjoc. 6.82 